\begin{tabular}{|c|c|c|c|}
\hline \multicolumn{4}{|c|}{ Where have all the young academic clinicians gone? } \\
\hline \multicolumn{4}{|c|}{ Number of academic staff in 21 UK medical schools } \\
\hline Grade & $1991 / 2$ & $1995 / 6$ & Percent change \\
\hline Professors & 497 & 614 & $+24 \%$ \\
\hline Readers & 111 & 119 & + $7 \%$ \\
\hline Senior lecturers & 916 & 1092 & + $19 \%$ \\
\hline Lecturers & 685 & 665 & $-3 \%$ \\
\hline Total & 2209 & 2490 & $+13 \%$ \\
\hline
\end{tabular}

Note: Medical student numbers rose by $14 \%$ over the same period Source: CVCP 1997

uation in the future".

The task force says that between the academic years 1991/92 and 1995/96, while the number of full professors in Britain's 21 medical schools increased by 24 per cent, the number of lecturers the first rung on the academic ladder fell by 3 per cent, an indication of the ex- tent to which academic careers are losing their attractiveness. At the same time, the amount of time needed for patient care has increased, says the report, partly because of increased pressure on resources within the reformed National Health Service, and the number of medical students has risen (see Table).

The task force commissioned a survey of almost 1900 medical academics and specialist registrars in four regions from two researchers at the University of Oxford's Unit of Health Care Epidemiology. About 900 forms were returned. The survey found that when young doctors feel under heavy pressure to meet their clinical commitments to the NHS, the activity that suffers most is research.

"The difficulty is that both clinical practice and teaching require fixed time commitments," says Lucy Wedderburn of the Institute of Child Health in London. "Research has to be squeezed in around these other commitments." In the long term, says Wedderburn, this research could begin to appear second-rate and individuals with academic interests would go elsewhere, particularly the US.

The task force wants employment contracts issued by the NHS and universities to specify the amounts of time to be spent on research and on clinical activities. It also recommends that any increase in the number of medical students should be accompanied by an increase in clinical academic staff.

DAVID DICKSON London

\title{
Summer of protest as Italian academics defend basic research
}

Italian scientists are embroiled in a furious protest over what they believe is the beginning of a radical reform of the country's scientific infrastructure at the expense of basic research. Leading scientists have criticised the research minister, Luigi Berlinguer, who has given them to understand that he wants to shift the focus of the National Research Council, the CNR, towards applied science. Currently, the council supports mainly basic research.

In a series of letters in the national daily, La Stampa, and the journal Science over the past few weeks, the scientists have warned Berlinguer against the move. They argue that his strategy is out of step with that of other countries such as the United States and Japan, whose governments are, they believe, more committed to supporting basic science.

The seeds of the protest were sown in the spring. Berlinguer appointed a technologist, Lucio Bianco, to head the National Research Council. Bianco, the brother of a political leader in the Italian Left majority, is relatively unknown and worked as an informatics engineer for the CNR for 25 years before his appointment.Traditionally, the job has been held by scientists with solid credentials in basic research. But in an interview with Science, Berlinguer said that

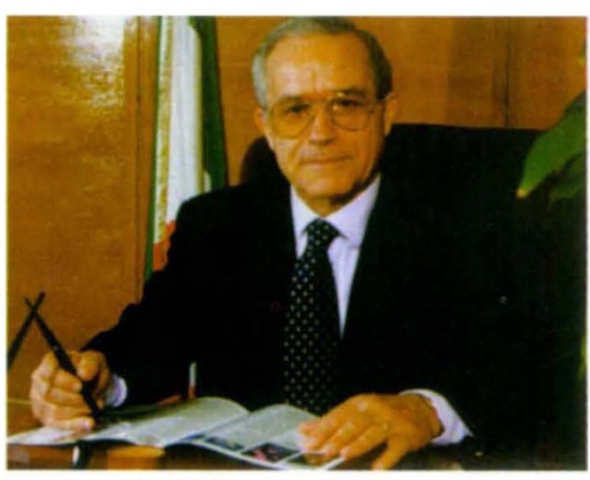

Lucio Bianco

Bianco was "perfect" for the job "since he has a long experience in applied research". And he added that the CNR "should not be carrying out basic research, but applied" (Science 275, 1871, 1997).

Now a dossier of letters protesting at this view has appeared in La Stampa, together with one in Science signed by six researchers, including members of the committees for biomedicine and biotechnology at the CNR (Science 276, 1771, 1997).

"A radical shift of CNR research from basic to applied [science] would lead to a dangerous disconnection in the national scientific infrastructure and would foster a further cut in financing universities' fun- damental research," warned Jacopo Meldolesi, a neuroscientist, and Francesco Clementi, a molecular pharmacologist, both at the University of Milan, in an interview with Nature Medicine. Both researchers are signatories to the Science letter.

Berlinguer himself says he has been misinterpreted. "I never stated that the CNR should be transformed into an agency of applied research," he told Nature Medicine. Instead, he says, he wants to reform the Italian system for funding scientific research to enable universities, national research institutions and industry to form what he calls "a more complete and coordinated entity".

The reform programme may still be several months away. However, the upper house of Italy's parliament passed a separate bill at the end of June that also aims to foster links between basic research and industry and so tackle Italy's serious unemployment problem. The Bill says that the state will create special funds for small and medium-sized businesses to recruit graduate students and PhDs. And it will also allow researchers from publicly funded institutions to spend four or more years on secondment to industry.

MARTINA BALLMAIER Milan 